\title{
NASA REFAN PROGRAM STATUS
}

by K. L. Abdalla and J. A. Yuska

Lewis Research Center

Cleveland, Ohio 44135

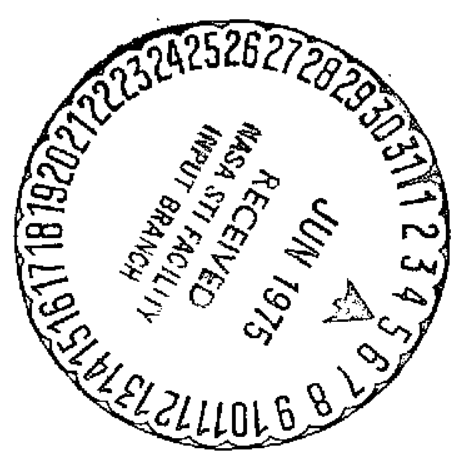

TECHNICAL PAPER to be presented at

Air Transportation Meeting sponsored by the

Society of Automotive Engineers

Hartford, Connecticut, May 6-8, 1975 


\title{
NASA REFAN PROGRAM STATUS
}

by K. L. Abdalla and J. A. Yuska

National Aeronautics and Space Administration

Lewis Research Center

Cleveland, Ohio

\begin{abstract}
The objective of the refan program is to demonstrate the technical feasibility of substantially reducing the noise levels of existing JT8D powered aircraft. The program consists of the design, manufacturing and testing of the refan engines and modified nacelles and airplanes. Experimental testing has been completed for the refan engine both at sea level and at altitude conditions. Ground testing for the B727 sideand center -engine installations and flight testing of the DC-9 with refan engines and acoustic nacelles have been performed. Analyses of the test results are in progress. Preliminary results presented in this paper show that substantial noise reductions were achieved.
\end{abstract}

\section{INTRODUCTION}

One of the major problems confronting civil aviation today is public exposure to noise generated by aircraft in the vicinity of airports. The principal sources of airport noise are identified with the large number of narrow-body aircraft representing about three-fourths of the domestic commercial fleet. The narrow-body aircraft fleet is comprised of the $D C-8$ 's and B707's powered by the JT3D turbofan engine and the DC-9's, B727 and B737's powered by the JT8D turbofan engine. The JT8D powered aircraft, which are newer and are still in production, are estimated to number about 1600 aircraft by 1985 compared to about 400 JT3D powered aircraft. A reduction of the noise in the JT8D powered aircraft, 
therefore, would represent a significant reduction in overall noise exposure in communities across the nation.

The present objective of the Refan Program, as described in references 1 and 2 , is to reduce the noise of the JT8D powered aircraft. The NASA has undertaken a program to establish the technical feasibility of substantially reducing the noise levels of JT8D powered aircraft with a minimum of engine and nacelle modifications. Contracts were let with Pratt and Whitney Aircraft (a division of United Aircraft Cor poration), manufacturer of the JT8D engine; Douglas Aircraft Company (a division of McDonnell Douglas Corporation), for the DC-9 airplane studies; and the Boeing Commercial Airplane Company (a division of the Boeing Company), for the B727 and B737 airplane studies. The results of the first phase of the program, which consisted primarily of a study definition and preliminary design, are summarized for each of the contractors' studies in references 3 to 5 . Engine and airframe changes, which would be required to make the engines quieter with a minimum of modifications, were identified. Engine changes consisted primarily of replacing the two-stage fan with a larger diameter single stage fan, while maintaining the existing engine core and its proven reliability. Airplane changes included new nacelles to accommodate the larger diameter engines and other changes to the aircraft structure due to the heavier installations.

The second phase of the program consisted of the detail design, manufacturing, and testing of the refan hardware. The test program included: (1) refan engine sea level static development tests at Pratt and Whitney Aircraft (P\&WA); (2) refan engine altitude tests at the Lewis Research Center; (3) ground tests of the baseline and the refan engines and modified side-engine and center-engine installations for the B727 at Boeing; and (4) flight testing of both the baseline and refanned DC -9 airplanes by Douglas. The overall program background, design considerations, and refan goals were discussed in reference 2. At that time the testing phase for the refan engines and the manufacturing phase for the modified nacelles and airplane were just beginning. After over 1200 hours of refan engine 
operations, the test program for the development of the refan engines both at sea level and altitude was completed. The ground tests of the B727 side-engine nacelle and center -engine installation, which were initiated early in January 1975, have also been completed. The flight test program of the DC-9 airplane with refanned engines and acoustic nacelles started one month ahead of schedule, on January 9, 1975. The tests were completed successfully early in March 1975, approximately two months ahead of schedule.

The purpose of this paper is to present the status of the Refan Program and to present some preliminary results of full scale engine testing at both sea level static and altitude conditions. Since the completion of the Douglas flight testing and Boeing ground testing coincided with the time of this writing, results from these tests could not be included in this report.

\section{TECHNICAL APPROACH}

The overall objective of the Refan Program is to provide engine and airframe modifications that will make the aircraft quieter. The changes were limited to minimize the cost of retrofit, and to maintain proven reliability of the JT8D engine. The basic approach to achieving lower engine noise was to replace the existing low-bypass ratio engine two-stage fan with a larger single-stage fan designed with low noise features.

Changes to the engine were limited to the fan and low pressure compressor stage, the fan-drive turbine, turbine exhaust section and acoustically treated fan duct. The hardware and general operating characteristics of the core engine were maintained while providing higher thrust and a higher bypass ratio engine. The engine features a full-length fan duct which provides considerable surface area for acoustic treatment. The inlet and tailpipe of the new nacelles provide additional surface area for sound treatment. 
Engine Modifications

Engine modifications for the JT8D engine were determined during the preliminary design phase as a result of extensive engine cycle studies performed by Pratt and Whitney Aircraft (P\&WA). The results of these studies were discussed in detail in reference 3 . The current production JT8D-9 engine was chosen early in the program as the baseline configuration for the comparison with the characteristics of the new refan engine. The refan version of the JT8D-9 engine is designated as a JT8D-109. For comparison a cross-section of the refan engine and the existing production engine is shown in figure 1 . The main changes in the refan design are the replacement of the two fan.stages with a larger diameter single-stage fan and the addition of two low compressor supercharging stages to maintain core engine pressure ratio and airflow capabilities lost by eliminating the second fan stage. To provide the additional power necessary for the new fan and low pressure compressor, more energy was extracted from the turbine. Therefore, the fourth stage turbine flow area was increased with the forward stages absorbing the increased loading.

Typical design characteristics for the refan JT8D-109 engine are compared with the design characteristics for the JT8D-9 in Table I. The design thrust increased about 15 percent from 14500 to 16600 pounds. The fan diameter increased about 8.7 inches with the bypass ratio nearly doubling. The mixed jet velocity was decreased from 1470 feet per second to 1140 feet per second. The engine dry weight increased approximately 562 pounds.

\section{Nacelle Modifications}

Douglas and Boeing used the results of the refan JT8D-109 engine design to perform detailed analyses and to design nacelle systems to accommodate the heavier and larger-diameter refan engines. The Douglas DC-9 refan nacelle configuration with the JT8D-109 engine installed is shown in figure 2 compared to the production nacelle with the 
JT8D-9 engine. The overall length of the refan nacelle is 261 inches, an increase of 59 inches over the production nacelle. Most of the increase in length is in the inlet section which provides surface area for acoustic treatment. The maximum diameter has increased from 53 inches for the production nacelle to 64 inches for the refan.

The Boeing B727 refan nacelle configurations with the JT8D-109 engines installed are shown in figure 3 for the side-mounted engines and in figure 4 for the center-engine installation. The overall length of the refan side-engine nacelle is 234 inches, an increase of 19 inches over the production nacelle. This nacelle was limited in inlet length (see fig. 4) due to the position of the existing B727 galley service door. The center-engine installation was unique since it required the addition of a new inlet and inlet duct to provide increased airflow to the refan engine.

Early studies showed that the B737 under -the-wing nacelle configuration was nearly identical to the $B 727$ side nacelle, except for additional length in the tailpipe. Because of this similarity and for budgetary reasons, further detailed work on the B737 nacelles was discontinued.

\section{Aircraft Modifications}

Changes to the basic airframe associated with installation of the larger and heavier nacelles consist of aerodynamic and structural modifications to the pylon and fuselage for the side-engines of both the DC-9 and B727. New side-engine mounts are required to accommodate the increased weight and nacelle diameter.

Additional modifications were required to the B727 airframe structure. These modifications involved the installation of the enlarged $\mathrm{S}$-duct and center engine. This rework involved alteration to several body bulkheads and frames to permit installation of the larger S-duct. The majority of the structural changes to both airplanes affected the aft-body structure where the new nacelles are attached. Forward body and wing structure changes were minimal and were limited to minor reinforcements. 
Several airplane configurations exist for both the DC-9 and B727 aircraft. In order to determine the relative performance characteristics before and after retrofitting, baseline airplane configurations were chosen. The DC-9-32 and the B727-200 series airplanes for the Douglas and Boeing aircraft, respectively, were the baseline airplanes used throughout this program.

\section{Acoustic Design Considerations}

Engine acoustic treatment. - Design of the fan duct acoustic treatment (fig. 5) is based on an analytical procedure developed at P\&WA: The acoustic treatment provided in the outer wall of the engine flowpath between the inlet guide vane and fan was designed to attenuate buzzsaw noise which is present in the inlet noise spectra over the higher portion of the engine operating range. Also shown in figure 5 is the acoustic treatment in the fan duct to reduce the levels of aft-propagating fan noise. The backing depth of most of this treatment was selected with a peak attenuation frequency in the $1 / 3$ octave band below the blade passage frequency corresponding to approach power setting. The remainder was tuned to the fan harmonic tone.

DC-9 aircraft. - Definition of the detailed acoustic treatment in the inlet and tailpipe of the DC -9 nacelle is based on Douglas prediction methods and Pratt and Whitney Aircraft - supplied engine cycle parameters. An acoustic design chart, based on approach conditions, was used to select treatment lengths that provide a balanced configuration for equal inlet and aft flyover noise. The resulting acoustic treatment is shown in figure 2. The details of the acoustic treatment were based on empirical data from DC-9 flyover noise tests, JT8D static engine tests, and laboratory flow duct transmission loss tests. The inlet treatment is tuned to the fan fundamental tone blade passage frequency at approach power. The tailpipe is tuned to attenuate both the fan harmonic tone and turbine noise, since for both the frequencies are nearly the same. 
B727 aircraft. - Treatment design parameters were obtained using lining design computer programs in which nacelle internal geometry, aerodynamic and acoustic parameters are input. The selected lining parameters were then used to predict the component attenuations achieved by various lining design configurations using a noise prediction program. The design point for the inlet acoustic treatment is the approach condition and is aimed for maximum attenuation at the fan fundamental blade passage frequency. The tailpipe is tuned to attenuate both the fan harmonic tone and turbine noise, since for both the frequencies are nearly the same. The resulting acoustic treatment for the B727 side engine nacelle is shown in figure 3 .

A description of the acoustic lining in the B727 center duct is provided in figure 6 . Treatment areas near the engine (S-1 and $S-2)$ are directed at reducing the buzzsaw noise, while treatment areas further forward (S-3 through $S-5$ ) reduce the fan tone noise.

\section{TEST PROGRAMS}

Ext ensive test programs were conducted in the development of the JT8D refan engine and its installation in the JT8D powered aircraft. These test programs included (1) uninstalled engine tests at P\&WA (fig. 7(a)) and NASA/Lewis Research Center (fig. 7(b)), (2) ground testing by Boeing with side - and center -engine installations designed for the B727 (fig. 7(c)), and (3) flight testing by Douglas with a modified DC -9 airplane (fig. $7(\mathrm{~d}))$.

Six refan engines were utilized in this program as shown in Table II. As indicated in the table, all tests have been completed. Preliminary data analyses have been completed for some of the tests, as noted in the table. A general description of the engine development tests, as denoted for engine number 1 through number 3 in the table, are discussed in this paper. In addition, the results for which the data are available are also included. For the flight tests and ground tests performed by the airframe 
contractors, the data analyses are not completed, and therefore, the results of these tests could not be incorporated in this paper.

Two of the JT8D-109 refan engines were tested at P\&WA in an outdoor acoustic test facility, as indicated in Table II. Far field noise measurements were obtained for both treated and untreated engine configurations. Also tested were configurations designed to measure fan, core, turbine and jet noise with particular emphasis on obtaining low frequency core noise. As noted in Table II, results have been analyzed for the test indicated with engine number 3 in the table, and the results for this test are presented in this paper.

In addition to the engine test program, a supporting program consisting of model and technology tests was conducted as a necessary part of the overall refan development program. Engine component tests per formed at P\&WA, included a full-scale fan and low-pressure compressor test, fan blade containment tests, and structural and dynamic component tests. Model tests were conducted at the Lewis Research Center of a 20 -inch scale model of the fan design with and without a model of the $\mathrm{S}$-duct inlet for the B727 center-engine installation. Wind tunnel model tests were conducted both by Douglas and Boeing to study drag, interference, stability, and control effects of the new, larger nacelles on the airplane aerodynamic characteristics. Other model tests were performed by the airframe contractors to study thrust reverser characteristics, nozzle performance and acoustics, and structural integrity of the modified airplane and components. Figure 8 shows photographs of some of these supporting technology tests.

\section{RESULTS}

\section{Refan Engine Development Tests}

Full scale testing for the development of the refan engines, with the goal of establishing flightworthiness of the JT8D-109 refan engines by December of 1974, was initiated on February 28, 1974 when the first experimental refan engine was tested. Establishment of flightwor thiness 
by December of 1974 was necessary in order to meet the planned DC-9 flight test date of February 1975. During the ten month development period, over 1000 hours of engine testing were accomplished at P\&WA utilizing three experimental test engines. One of these three engines was a new production JT8D-9 engine which was retrofitted to the refan JT8D-109 configuration after baseline JT8D tests were performed. This production-quality refan engine, after sea level performance tests were accomplished at P\&WA, was shipped to the LeRC altitude test facility in Cleveland, Ohio, where it was tested for over 200 hours at altitude conditions. The engine performance results presented later in this report utilized the data obtained from this production-quality engine in both the JT8D-9 and the refan JT8D-109 configurations.

Upon completion of engine tests performed during the development period, the refan JT8D-109 engines were assessed as suitable for experimental flight testing in a DC-9 aircraft modified for the refanned engines. The letter establishing flightworthiness was written on December 20, 1974 and the flight tests were initiated one month ahead of schedule on January 9,1975 . A detailed description of all the development tests and their results is beyond the scope of this paper. A general description of the major tests performed, however, are included.

A summary of the major full scale development tests performed with all three experimental test engines is given in Table III. The tests included evaluations of stress and performance, endurance and system compatibility of the DC-9/JT8D-109. Approximately 610 hours (Table III) of stress and performance testing were accumulated. Stress evaluation tests were conducted to ensure flutter and vibration-free en gine operation. Results of these stress evaluations showed that vibratory stresses on the unique refan hardware were acceptable and that no fan blade flutter was observed over the operating range. Performance tests were conducted to verify design performance and engine operational characteristics over the required airplane operating envelope, including altitude conditions. All operational characteristics were verified and engine 
performance was satisfactory: A summary of the major performance parameters of interest is presented later in this paper.

Two types of endurance tests, namely low cycle fatigue and duty cycle, were performed totalling 350 hours of engine operation. Low cycle fatigue (LCF) tests were performed to evaluate the structural design of the unique refan hardware to withstand worst engine conditions and to determine engine durability. These LCF tests were accomplished in two 100 -hour series of 1000 cycles each. The purpose of the first series of LCF tests was to check the initial design of the new refan hardware. The second series utilized hardware that was modified as a result of the first test series. The hardware design evaluated in the second LCF series was the same design as incorporated in the flight engines. Inspection of engine parts after LCF tests showed the refan hardware to be in good condition, based on JT8D-9 experience. The duty cycle ty pe of endurance test consisted of $25 \mathrm{cy}$ cles of engine operation, each cycle being six hours in duration. The duty cycles simulated typical airplane utilization cycles including taxiing, takeoff, landing, etc. The duty cycle endurance test, totalling 150 hours in duration, was conducted in accordance with FAA procedure, FAR Part 33. All test objectives of the duty cycle endurance test were met.

The DC-9/JT8D-109 system compatibility tests (approximately $90 \mathrm{hr}$ of engine testing) were performed to determine the compatibility of the DC-9 designed refan inlet, exhaust duct, and thrust reverser systems with the JT8D-109 engine. The exhaust nozzle was sized to provide correct engine match characteristics. Distortion tests with the flight inlet indicated that the distortion levels were within the acceptable limits established for the engine operation with no significant changes in engine performance over the operating range of the engine. Tests to determine effects of accessory cooling, bleed performance, and vibration levels on engine performance showed that the engine and nacelle systems operated within analytical prediction. Performance tests of the refan engine with the Douglas thrust reverser installed, including reverser 
cyclic and failsafe operations were completed successfully within the requirements of the test plan.

\section{Engine Performance}

Sea level static results. - A production-quality JT8D-9 engine was utilized in this program, as discussed earlier, to obtain baseline engine performance data to compare with the refan results. After baseline tests were performed with this engine, it was modified to the JT8D-109 refan configuration, and performance tests were again obtained. Results for both the baseline JT8D-9 test engine (typical of current production engines) and the same core engine converted to the JT8D-109 refan configuration are summarized in Table IV for their respective sea level static takeoff conditions. As shown in the table, takeoff thrust for the JT8D-9 engine is 14500 pounds, while for the refan test engine, it is 16600 pounds.

The engine pressure ratio at the static takeoff conditions shown in Table IV is 2.15 for the baseline JT8D-9 engine and 1.75 for the JT8D-109 refan engine. The total airflow increased from 317 pounds per second for the baseline engine to 468 for the refan. These results for airflow agree favorably with the design values of 319 and 467 pounds per second given in Table $I$. The by pass ratio increased from 0.95 for the JT8D-9 to 2.12 for the refan engine, compared to the design values of 1.05 and 2.03, respectively. Engine low rotor speed for the refan is $7350 \mathrm{rpm}$ compared to 8020 for the JT8D-9. These values are lower than the design predictions listed in Table I namely $7450 \mathrm{rpm}$ for refan, and 8040 for the baseline engine.

A comparison of specific fuel consumption for the uninstalled engines for sea level static conditions is shown in figure 9 . Note that, as the engine cycle studies predicted, the refan engine has a lower specific fuel consumption over the entire thrust range compared to the baseline JT8D-9. The effects on installation of the engines in the nacelles and airplanes are discussed later. 
Altitude test results. - The production-quality JT8D-109 refan engine was also tested at altitude conditions in the Propulsion Systems Laboratory Facility at the Lewis Research Center (fig. 7(b)). No altitude data were obtained in this program, however, for this engine as a baseline JT8D-9. In order to compare the altitude data for the refan engine with this same engine as a JT8D-9, the sea level data for the baseline JT8D-9 were analyzed via computerized simulation and its performance at altitude was estimated by the engine contractor. These results, along with the actual data for the JT8D-109 refan are compared in figure 10. Presented in this figure is the specific fuel consumption for both engines at a typical altitude-cruise condition of 30.000 feet and Mach number of 0.8 . Over the typical aircraft cruise range shown in the figure, the uninstalled refan engine shows a slight improvement in specific fuel consumption. At a value of 4000 pounds of thrust, for example, the refan fuel consumption is 1 percent less than the baseline engine. At the maximum cruise thrust for each engine depicted in the figure, the refan improvement is about $1 / 2$ percent.

\section{Installed Engine Performance}

Calculations were made by the NASA of the performance of the JT8D-109 refan engine and of the baseline JT8D-9 installed on both the DC -9-32 and the B727-200 aircraft for takeoff thrust and cruise thrust specific fuel consumption (TSFC). The takeoff thrust was calculated for sea level conditions at a Mach number of 0.27 . The cruise condition for both aircraft was determined at an altitude of 30000 feet and a Mach number of 0.80 . The installed cruise thrust at these conditions was estimated at 3600 pounds for the DC $-9-32$, and 4000 pounds for the B727-200.

The data used to calculate the uninstalled performance were obtained from the baseline and refan engines tested in this program (Table II, engine 1 and $1 \mathrm{~A}$ ). Installation effects (estimated by the airframe contractors) were then taken into account. Effects considered include losses resulting 
from internal flow in the inlet and tailpipe and the effect of bleed and power extraction. External drag changes resulting from changes in engine/nacelle diameter and length are considered in airplane performance calculations.

The results of the installed engine performance calculations are summarized in Table $\mathrm{V}$. The installed takeoff thrust as shown in the table is about 6 percent higher for the refan engine than for the baseline engine. At cruise, the refan engine shows an improvement in uninstalled TSFC of about 1 percent compared to the baseline. However, increased installation losses for both the DC-9 and B727 eliminate all or nearly all the gain, such that the installed cruise TSFC for the refan is nearly equivalent to the baseline engine.

\section{Airplane Performance}

In the early phases of the refan program, engine and aircraft performance predictions were made by the respective engine and aircraft manufacturers. These predictions were based on preliminary engine design characteristics, integrated with airplane mission analytical procedures using computer simulations. The results of these studies which estimated the performance for the refan DC-9-32 and B727-200 aircraft were described in reference 2. Subsequently, aircraft performance predictions have been updated by the airframe contractors based on data from wind tunnel tests and more recent engine perfor mance estimates by P\&WA. At the time of this writing, detailed airplane performance estimates by the airframe contractors based on the altitude data for the refan engine presented herein were not yet available. The airplane performance presented in this report, therefore, is based on engine and airplane data prior to the completion of refan engine altitude tests.

DC-9-32 aircraft. - Airplane performance for the DC-9 -32 refan aircraft is compared to the current production JT8D-9 powered airplane in figure 11. Shown in this figure is the payload/range envelope for the high-speed cruise condition of Mach number of 0.78 and an altitude of 30000 feet. The figure delineates the operational weight limits of the 
aircraft for this cruise condition as a function of range. The gross weight of both configurations is 108000 pounds, which is the certification weight of the production DC-9-32/JT8D-9 aircraft.

As shown in the figure, the refan aircraft range is about the same as the production aircraft range for payloads up to about 19000 pounds. For the higher payloads the refan shows some range loss. At 100 percent load factor (23 000-1b payload or 115 passengers), the range loss is 165 nautical miles. The range loss at the higher payloads is due to a 2482 pound increase in operating empty weight for the refan aircraft, and to the gross weight limit of 108000 pounds. Studies to determine increased gross weight requirements for the refan to offset this range loss were not performed for this airplane. However, the range loss occurs only for high load factors (above 80 percent). Most missions are of considerably less than maximum range and, therefore, can be performed without this restriction on payload.

B727-200 aircraft. - This refan aircraft, when compared to the production JT8D-9 aircraft for the same gross weight of 172500 pounds, also suffers a maximum range loss at high payloads due to the increase in operating empty weight. However, since this aircraft, as an option, has already been certified for the current production airplane with gross weights up to 182500 pounds, trade studies were performed for the refan aircraft to determine optimum weight, payload, and range characteristics. Results of the trade studies for the weight growth limit of 182500 pounds for the refan aircraft are shown in figure 12 . The figure contains the payload/range curve for the typical high speed cruise condition for this aircraft at a Mach number of 0.84 and an altitude of 30000 feet. Note that for the production $727-200 / J T 8 D-9$ aircraft, the gross weight is 172500 pounds.

As shown in the figure, the refanned aircraft can provide considerable range gain at the higher payloads (above about $23000 \mathrm{lb}$ ) if the higher gross weight limit is used. At 100 percent load factor (27 500-lb payload or 134 passengers), the refan has a range increase of 225 nautical miles compared to the production aircraft (as noted in the table in fig. 12). This is 
a result of the gross weight increase, which also resulted in an operating empty weight increase of 3440 pounds for the refan. A slight range loss for the refan occurs for payloads below 23000 pounds. For example, at a load factor of 55 percent (15 000-1b payload or 74 passengers), the range for the refan aircraft is 20 nautical miles less than the production aircraft.

\section{Acoustic Performance}

JT8D-109 engine. - Results are available, as discussed earlier, for one of the refan engines tested at P\&WA. The test configuration was the JT8D-109 refan engine with a fully-treated fan case and duct as shown in figure 5 . The engine was tested with a hardwall, bellmouthtype inlet and an untreated nozzle. A photograph of this refan engine is shown in figure 13 as it was installed in the outdoor acoustic test facility at P\&WA.

The results for the test with this refan engine configuration are presented in figure 14 . The peak inlet and peak aft noise at the 200 -foot sideline condition is given as a function of engine corrected static thrust (power setting). For comparison, the prediction for the refan engine based on design criteria is included in the figure, as well as the noise characteristics for the existing production JT8D-9 engines. The maximum perceived inlet noise level measured for the refan engine (fig. 14(a)) was generally lower than the predicted values and considerably lower than for the production engine. The measured aft noise (fig. 14(b)) for the refan engine generally was as predicted, and about $5 \mathrm{~dB}$ below the production engine over the entire thrust range.

Airplane acoustic performance. - Flyover noise level estimates were made by the airplane manufacturers for their respective aircraft. These estimates were based on noise component analyses and the acoustic data from refan engine noise tests at P\&WA discussed in the previous section. The analyses accounted for effects of suppression in the acoustically treated nacelles. In addition, preliminary refan engine acoustic data were 
run at P\&WA for a treated inlet and treated tailpipe configuration similar to the DC-9 nacelles (see fig. 2). These data were incorporated by Douglas into the noise level comparison for the DC-9 aircraft.

The refan noise levels resulting from these analyses are compared to the production aircraft levels, the corresponding FAR Part 36 standards and the wide-body DC-10-10 in figure 15. The noise estimates, which are based on refan engine acoustic data, show that the refan aircraft are considerably quieter than the production aircraft. The refan DC-9-32 provides a reduction of 6 to $10 \mathrm{EPNdB}$ compared to either the production aircraft or FAR Part 36 . The refan B727-200 is 7 to $7 \frac{1}{2}$ EPNdB quieter than the production aircraft and 2 to $11 \frac{1}{2}$ EPNdB below FAR Part 36 . As shown in the figure, the $2 \mathrm{EPNdB}$ value is for the approach condition.

Early in the Boeing studies (ref. 2), a possible need for additional acoustic attenuation was considered by including, as one design option, a configuration with a treated inlet ring and a treated fan/primary exhaust splitter. Detailed acoustic tests have just recently been performed at the Boeing noise facility (fig. 16) both with and without the inlet ring configuration. If it should be desirable, the ring design is available for incorporation into the $B 727$ refan nacelle.

Compared to the relatively quiet wide-body $\mathrm{DC}-10$, the refan air craft show lower noise levels for the measuring conditions shown. Note that the DC-10 takeoff is with full power, to agree with the way the FAR Part 36 certification levels were measured for this aircraft.

Airplane noise contour areas. - Noise contour areas provide a more complete indication of community exposure and the noise reduction benefits of refanning. EPNL noise contours have been calculated by the NASA for the refan and production aircraft. These areas were calculated based on the refan engine acoustic data installed in their respective aircraft with installation effects, for a FAR Part-36 cutback certification takeoff profile and a single segment approach on a three-degree glide slope. Takeoff gross weights were 108000 pounds for the DC-9 and 172500 pounds for 
the B727. The resulting areas of these contours are summarized for the DC-9-32 in figure 17 and for the B727-200 in figure 18. The DC-10-10 contour areas are included for comparison. Again, note that a full power takeoff profile was used for the DC -10 .

As indicated in figures 17 and 18, the refan aircraft provide substantial reductions in noise exposure contour area compared to the narrow-body production aircraft. At a noise exposure level of $90 \mathrm{EPNdB}$, the contour area for the DC $-9-32$ aircraft would be reduced

from about $7 \frac{1}{2}$ square miles to three square miles. Similarly, for the B727-200 aircraft, the contour area is reduced from 28 square miles to a little over 7 square miles, which is a reduction of 74 percent.

The DC-9 airplane with refanned engines and modified acoustic nacelles (fig. 19) has recently completed flight testing at the Yuma, Arizona test site. Flyover noise and airplane performance were obtained during these flights. Analysis of the flight test data will provide actual noise and performance of the DC -9 refan airplane.

\section{CONCLUDING REMARKS}

All of the major milestones of the Refan Program have been successfully accomplished. The final analyses of the recently completed engine noise tests at P\&WA, of the refan ground tests of the Boeing B727 nacelle configurations, and of the DC -9 refan flight tests should be completed by mid-1975. Generally, the overall goals of the Refan Program have been achieved, namely, providing a significant noise reduction of the JT8D powered aircraft by refanning, with little or no degradation in airplane performance.

Results of tests for the refan JT8D-109 engine show that at cruise conditions, the refan engine provides a small improvement in uninstalled TSFC compared to the JT8D-9 engine. Increased installation losses for both the DC-9 and B727 eliminate all or nearly all the gain such that the installed specific fuel consumption for both the refanned aircraft for typical 
altitude cruise conditions are nearly identical to the current produc tion aircraft. Typical range/payload missions are nearly unaffected, except near full load capacity. For the refanned DC-9, a range loss occurs at full load; for the $\mathrm{B727}$, a range gain can be achieved by utilizing the option of increasing the gross weight.

Substantial noise reduction using the refan concept has been shown to be technically feasible. Noise reduction compared to existing aircraft at the FAR Part 36 measuring stations estimated from actual refan engine ground acoustic data are 6 to $10 \mathrm{EPNdB}$ for the DC-9 and approximately $7 \mathrm{EPNdB}$ for the $\mathrm{B} 727$. These refan noise levels are lower than either the FAR Part 36 noise standards or the noise levels of the wide body DC-10-10. Substantial reductions in contour area exposure are also demonstrated.

\section{REFERENCES}

1. E. W. Sams and D. L. Bresnahan, "Refan Program. Phase I:

Summary Report:" National Aeronautics and Space Administration, TM X-71456, Oct. 1973.

2. L. E. Stitt and A. A. Medeiros, "Reduction of JT8D Powered Aircraft Noise by Engine Refanning." Presented at the Air Transport Meeting, Dallas, Tex., Apr. 30 - May 2, 1974.

3. "JT8D-100 Turbofan Engine, Phase I --Noise Reduction." Pratt and Whitney Aircraft, PWA-4790, 1974; also NASA CR-134654.

4. "DC-9/JT8D Refan Phase I -.- Technical and Economic Feasibility of Retrofitting DC-9 Aircraft with Refan Engine To Achieve Desired Acoustic Levels." Douglas Aircraft Co., Inc., MDC-J5738, Nov. 1973; also NASA CR-121252.

5. "Program on Ground Test of Modified, Quiet, Clean, JT3D and JT8D Turbofan Engines in Their Respective Nacelles --- Modification of Boeing 707, 727, and 737 Aircraft for Aircraft Noise Reduction." Boeing Commercial Airplane Co., D6-41244, Sept. 1973; also NASA CR- 134553. 


\section{TABLE I. - COMPARISON OF DESIGN CHARACTERISTICS}

FOR JT8D-9 AND REFAN JT8D -109 ENGINES

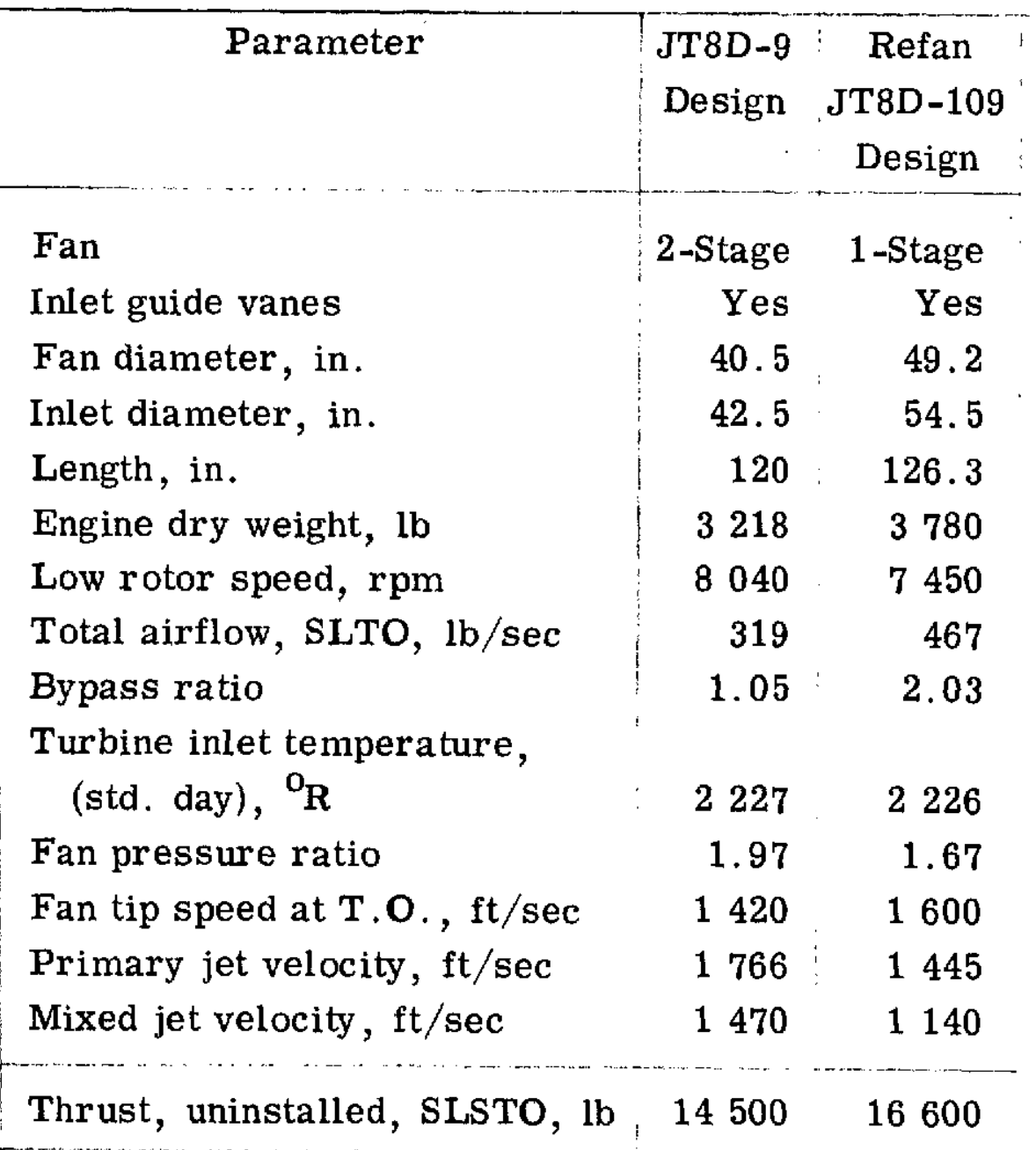


TABLE II - REFAN ENGINE TEST PROGRAM

\begin{tabular}{|c|c|c|c|c|}
\hline \multirow{2}{*}{$\begin{array}{l}\text { Engine } \\
\text { number }\end{array}$} & \multirow[t]{2}{*}{ Engine } & \multirow[t]{2}{*}{ Uninstalled engine tests } & \multicolumn{2}{|c|}{ Engine installation } \\
\hline & & & Location & Tests \\
\hline 1 & $\begin{array}{l}\text { JT8D-9 } \\
\text { (P\&WA) }\end{array}$ & Baseline performance ${ }^{a, b}$ & 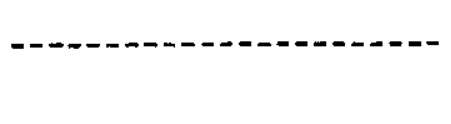 & - \\
\hline $1 \mathrm{~A}$ & $\begin{array}{c}\text { JT8D-109 } \\
\text { (from no. 1) }\end{array}$ & $\begin{array}{l}\text { SLS performance } \\
\text { at } P \& W A^{a, b} \\
\text { Altitude performance } \\
\text { at } \text { LeRC }^{a, b}\end{array}$ & $---n-1$ & -- \\
\hline 2 & $\begin{array}{l}\text { JT8D-109 } \\
(\mathrm{P} \& \mathrm{WA})\end{array}$ & $\begin{array}{l}\text { Acoustics }^{a} \\
\text { Performance, stress } \\
a, b\end{array}$ & - & - \\
\hline 3 & $\begin{array}{l}\text { JT8D-109 } \\
\text { (P\&WA) }\end{array}$ & $\begin{array}{l}\text { Acoustics }{ }^{a, b} \\
\text { Performance, stress }{ }^{a, b} \\
\text { Endurance } \\
a, b\end{array}$ & 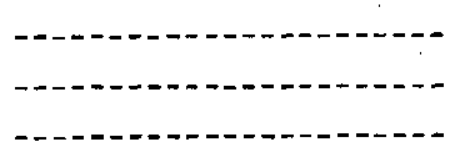 & 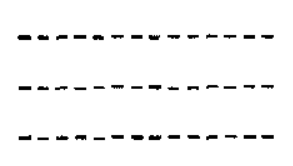 \\
\hline 4,5 & $\begin{array}{l}\text { JT8D -109 } \\
\text { (Douglas) }\end{array}$ & Performance calibration ${ }^{a}$ & $\begin{array}{l}\text { Side-engine installation } \\
\text { on } D C-9 \text { aircraft }\end{array}$ & $\begin{array}{l}\text { Flight tests: } \\
\text { Acoustics }^{a} \\
\text { Performance }^{a}\end{array}$ \\
\hline 6 & $\begin{array}{c}{ }^{c_{J T}} \text { 8D-115 } \\
\text { (Boeing) }\end{array}$ & Performance calibration $^{a}$ & $\begin{array}{l}\text { Side-engine, then center- } \\
\text { engine installation } \\
\text { for B727 }\end{array}$ & $\begin{array}{l}\text { Ground tests: } \\
\text { Acoustics }^{\mathrm{a}} \\
\text { Performance }^{\mathrm{a}}\end{array}$ \\
\hline
\end{tabular}

\footnotetext{
${ }^{a}$ Tests completed.

${ }^{b}$ Preliminary data analysis completed.

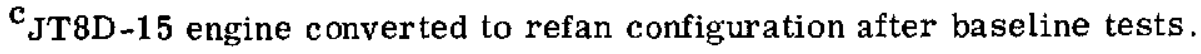


TABLE III. - REFAN ENGINE DEVELOPMENT TESTING

Type of test

Test duration

Stress and Performance

at sea level ............. . . . 410

(using three test engines)

Altitude performance, steady state and transients . . . . . . . . 200 (using one test engine)

Endurance

(using one test engine)

Low cycle fatigue . . . . . . . . . . . 200

Duty cycle . . . . . . . . . . . . 150

DC-9/JT8D-109 System

compatibility. . . . . . . . . . . 90

(using one test engine)

Total refan engine testing . . . . . . . 1050 


\section{TABLE IV. - SUMMARY OF UNINSTALLED ENGINE}

PERFORMANCE RESULTS AT SEA LEVEL STATIC

\section{TAKEOFF CONDITIONS, STANDARD DAY}

[Data based on tests with engines number 1 and $1 \mathrm{~A}$ at P\&WA.]

Parameter

Thrust, lb

TSFC, lb $/ \mathrm{hr} / \mathrm{lbf}$

Engine pressure ratio

Low rotor speed, rpm

High rotor speed, rpm

Corrected total airflow, $\mathrm{lb} / \mathrm{sec}$

Bypass ratio

Turbine inlet temperature, ${ }^{\circ} \mathbf{R}$
Test engine configuration

$$
\begin{array}{cc}
\text { Baseline } & \text { Refan } \\
\text { JT8D-9 } & \text { JT8D-109 }
\end{array}
$$

$14500 \quad 16600$

$0.578 \quad 0.508$

$2.15 \quad 1.75$

$8020 \quad 7350$

$11420 \quad 11380$

$317 \quad 468$

$\begin{array}{ll}.95 & 2.12\end{array}$

$2257 \quad 2280$ 
TABLE V. - CALCULATED ENGINE PERFORMANCE

(a) Takeoff thrust ( $M=0.27$ at sea level)

\begin{tabular}{|l|rr|rr|}
\hline \multicolumn{1}{|c|}{$\begin{array}{c}\text { Thrust, } \\
\text { lb }\end{array}$} & \multicolumn{2}{|c|}{ DC-9-32 } & \multicolumn{2}{|c}{ B727-200 } \\
& Production Refan & Production & Refan \\
\hline Uninstalled & 12400 & 13225 & 12400 & 13225 \\
Installed & 12185 & 12860 & 11920 & 12585 \\
\hline
\end{tabular}

(b) Cruise TSFC (Alt. $=30000 \mathrm{ft}, \mathrm{M}=0.80$ )

\begin{tabular}{|c|c|c|c|c|}
\hline \multirow[t]{2}{*}{$\begin{array}{c}\text { TSFC, } \\
\mathrm{lb} / \mathrm{hr} / \mathrm{lbf}\end{array}$} & \multicolumn{2}{|c|}{$\begin{array}{c}D C-9-32 \\
\left(F_{n}=3600 \mathrm{lb}\right)\end{array}$} & \multicolumn{2}{|c|}{$\begin{array}{c}B 727-200 \\
\left(F_{n}=4000 \mathrm{lb}\right)\end{array}$} \\
\hline & Production & Refan & Production & Refan \\
\hline Uninstalled & 0.811 & 0.803 & 0.815 & 0.806 \\
\hline Installed & .837 & .836 & .838 & .838 \\
\hline
\end{tabular}




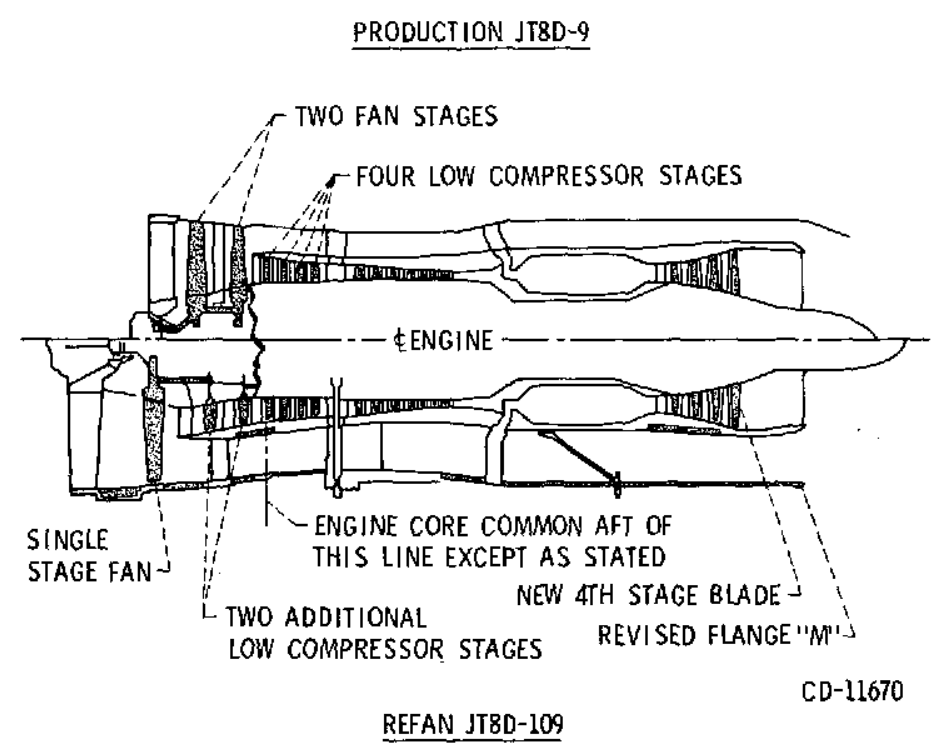

SOLID AREAS ON CASINGS INDICATE ACOUSTIC TREATMENT

Figure 1. - Engine comparison.

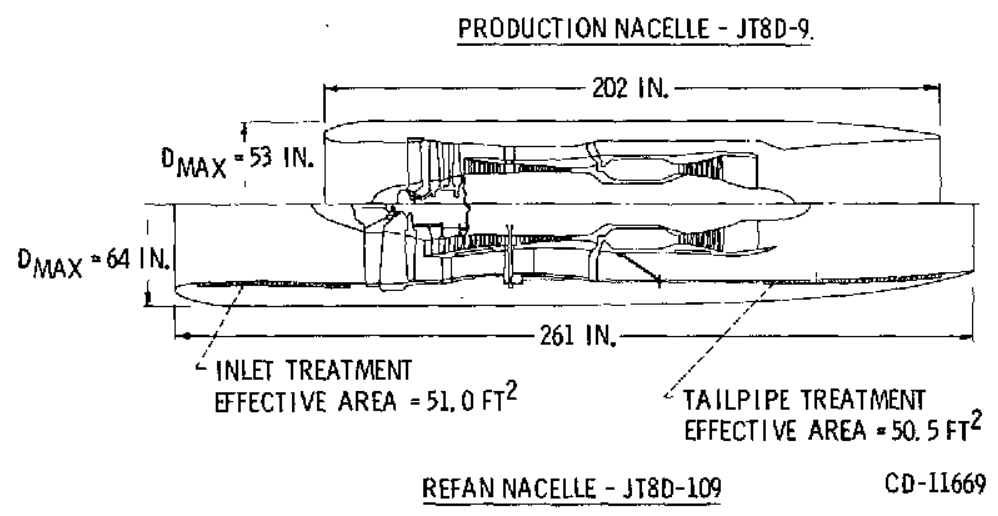

Figure 2. - Douglas DC-9 nacelle comparison. 
PRODUCTION NACELLE - JT8D-9

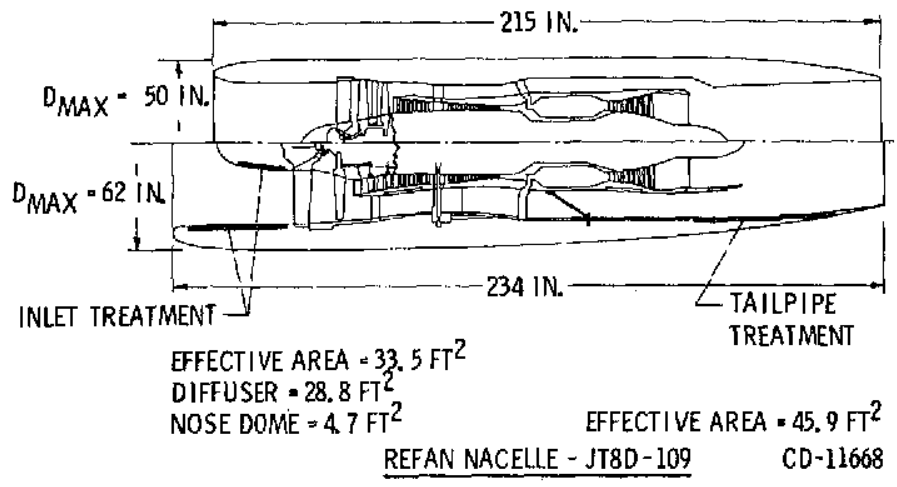

Figure 3. - Boeing 727 side-engine nacelle comparison.

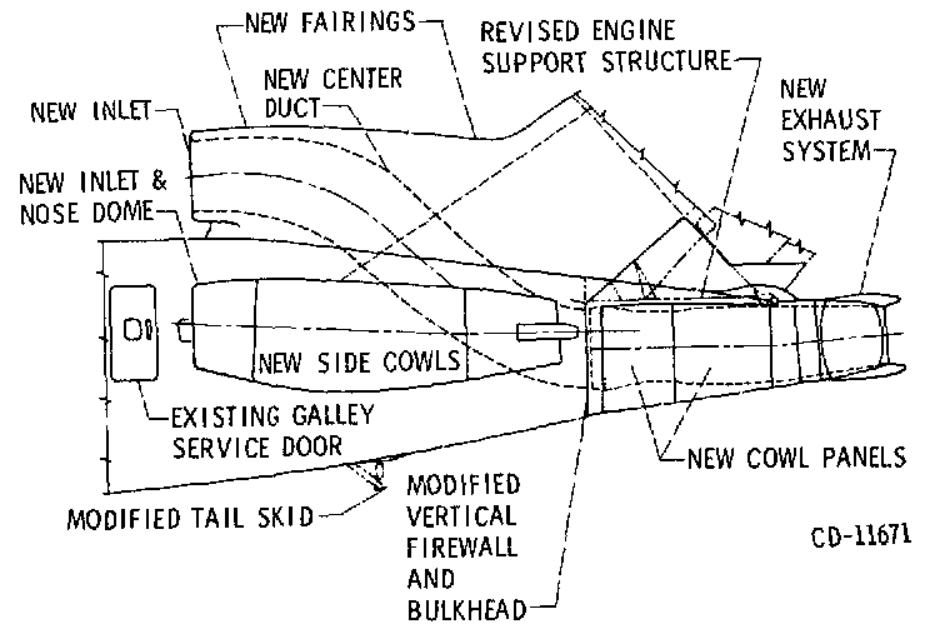

Figure 4. - JT8D-109 installation on B727-200. 


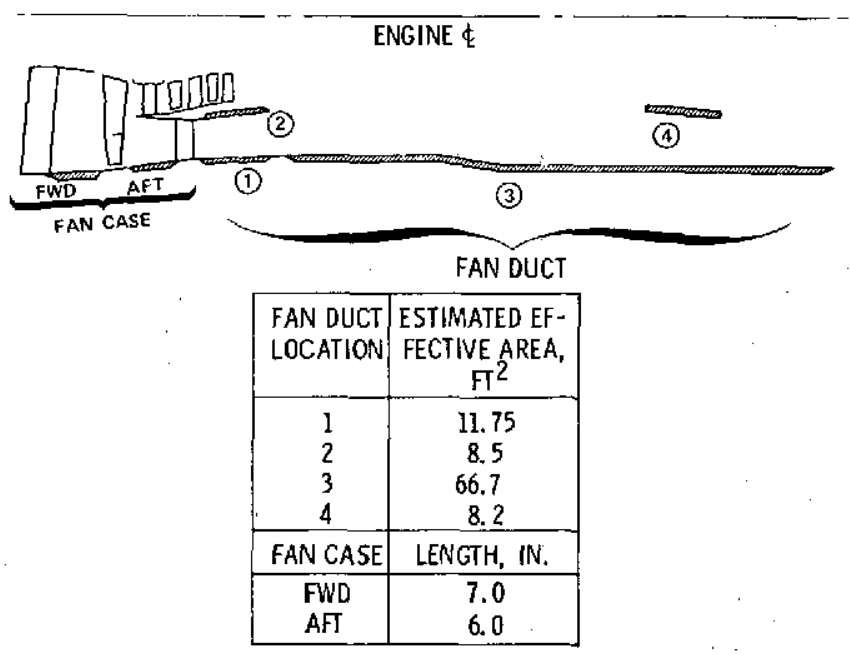

Figure 5. - P\&WA supplied acoustic treatment, installed in refan engines.

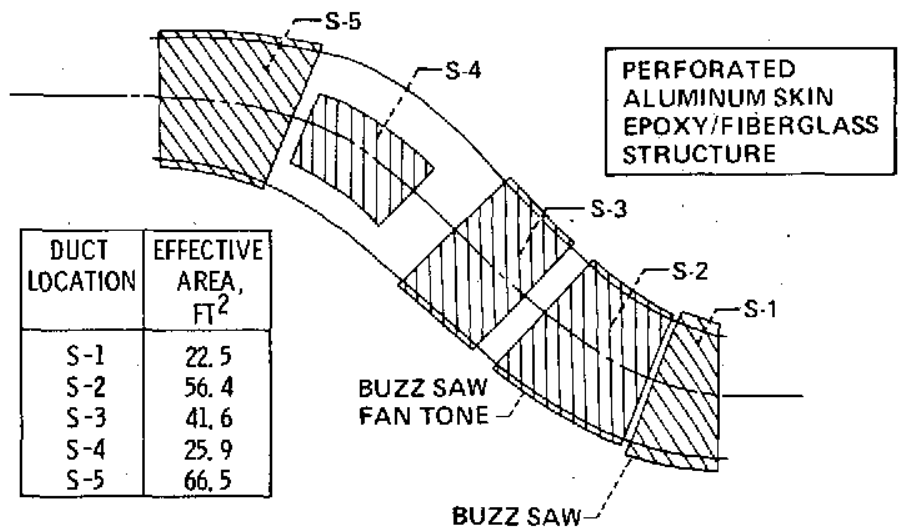

Figure 6. - B 727 acoustic lining description - center-engine inlet. 


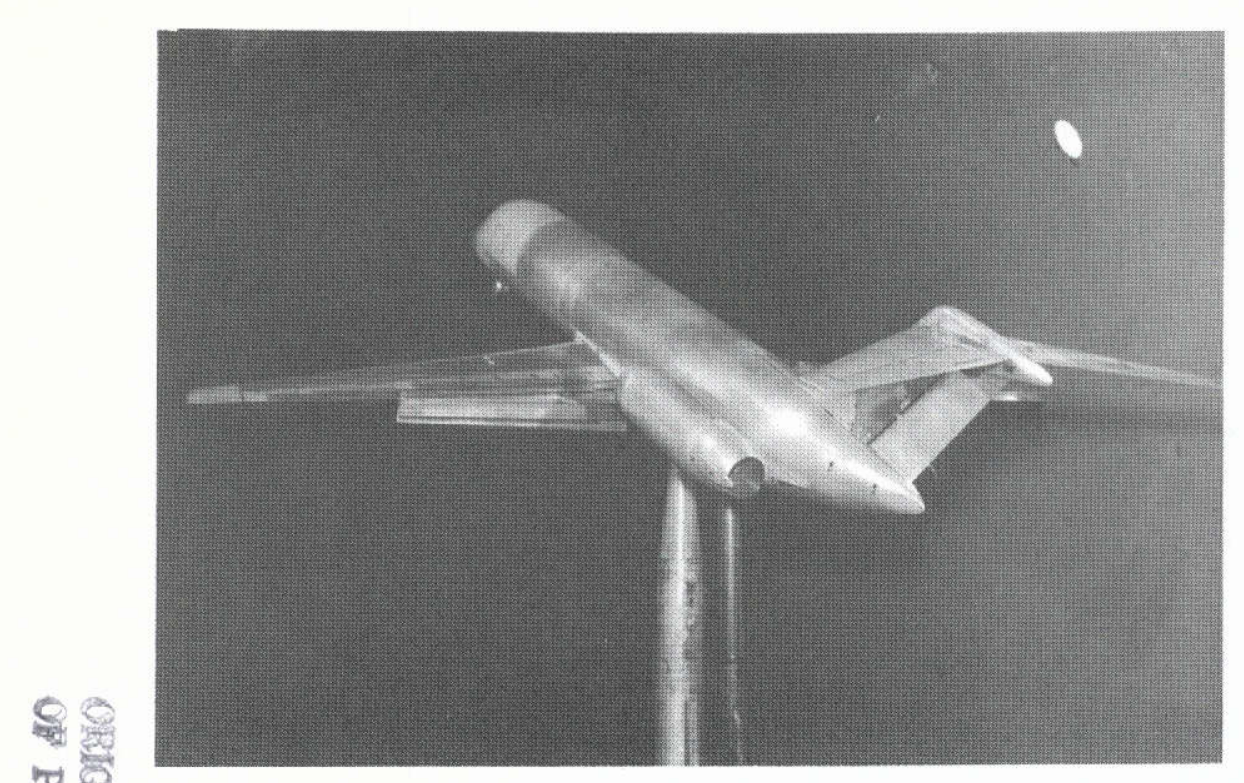

(a) Refan DC-9 model wind tunnel testing.

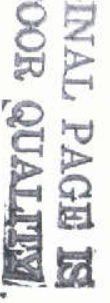

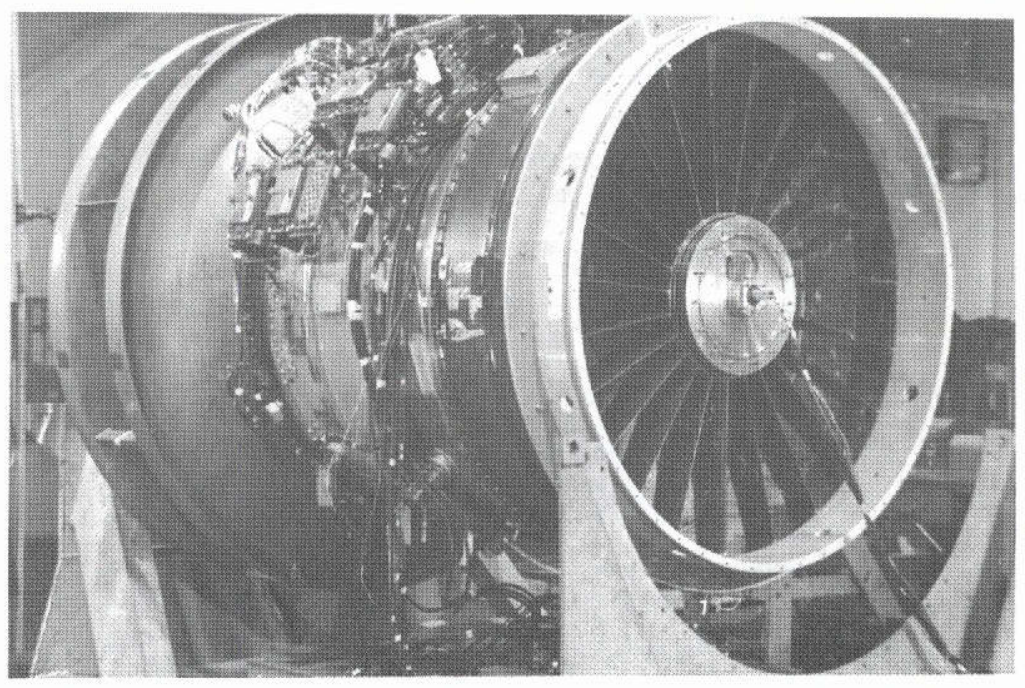

(b) Full-scale fan and low pressure compressor test rig for refan JT8D.

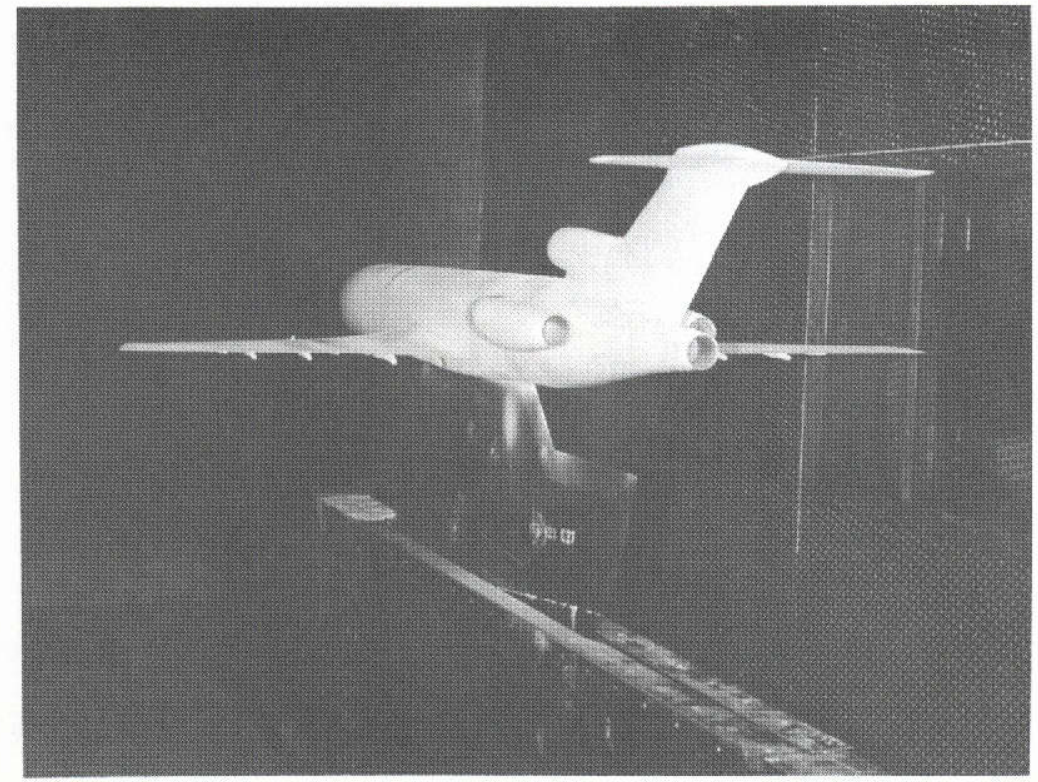

(d) Refan B727 model wind tunnel testing. 


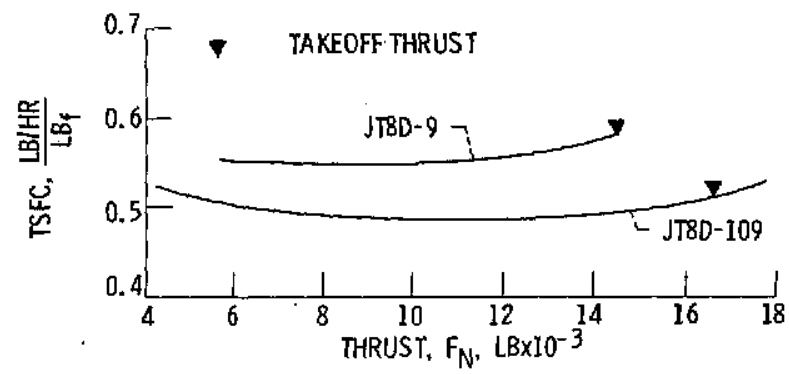

Figure 9 - Measured specific fuel consumption comparison for baseline JT8D- 9 and refan JT8D-109 uninstalled engines. Sea level static conditions, corrected to stand ard day; fuel lower heating value $=18,400 \mathrm{Btu} / \mathrm{lb}$.

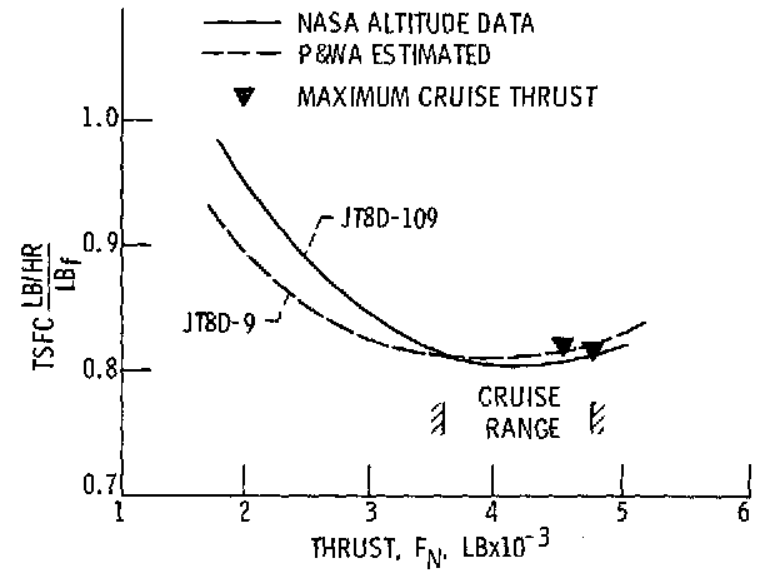

Figure 10. - Measured specific fuel consumption for the uninstalled refan J780-109 engine compared to estimated values for JPDD-9. Altitude 30,000 feet, Mach number, 0.8 ; standard day conditions. Fuel lower neating value $=18,400 \mathrm{Btul} / \mathrm{b}$. 
ENGINES GROSS WEIGHT, OPERATING LB EMPTY WEIGHT

$\begin{array}{lcc} & & \text { LB } \\ -\sim \text { JT8D-9 } & 108,000 & 59,076 \\ \text { JT8D-109 } & 108,000 & 61,558\end{array}$

\begin{tabular}{|c|c|}
\hline \multicolumn{2}{|c|}{ RANGE CHANGE FOR J JPD-9 } \\
TO JT8D-109. NAUTICAL MILES \\
\hline 100\% LOAD FACTOR & $5 \% \%$ LOAD FACTOR \\
$(23,000$ LB PAYLOAD $)$ & $(12,800$ LB PAYLOADI \\
\hline-165 & +15 \\
\hline
\end{tabular}

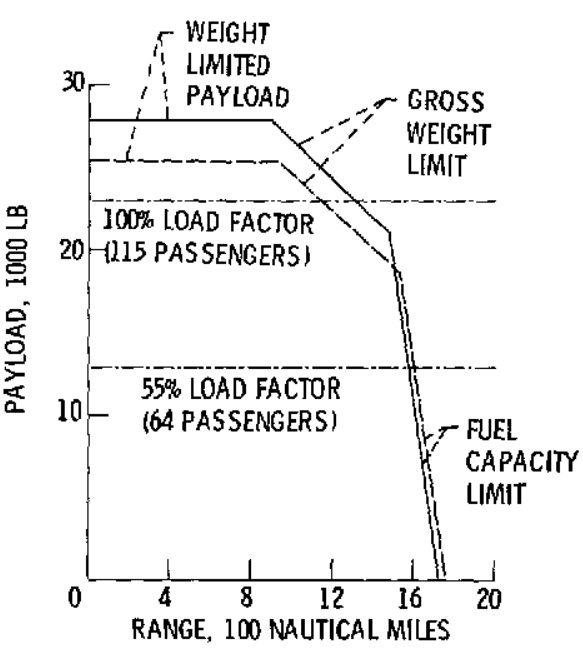

Figure 11. - DC- 9 - 32 payload/range characteristics. 0.78 Mach number, $30,000 \mathrm{ft}$, altitude, standard day.
ENGINES GROSS WEIGHT, OPERATING

LB EMPTY WEIGHT,

$\begin{array}{lrr}- \text { JT8D-9 } & 172,500 & 99,000 \\ --D \text { JT8D-109 } & 182,500 & 102,440\end{array}$

\begin{tabular}{|c|c|}
\hline \multicolumn{2}{|c|}{ RANGE CHANGE FOR JT8D-9 } \\
TO JT8D-10\%. NAUTICAL MILES \\
\hline $\begin{array}{c}\text { 100\% LOAD FACTOR } \\
(27,500 \text { LB PAYLOAD })\end{array}$ & $55 \%$ LOAD FACTOR \\
\hline 05, O00 LB PAYLOAD \\
\hline +225 & -20 \\
\hline
\end{tabular}

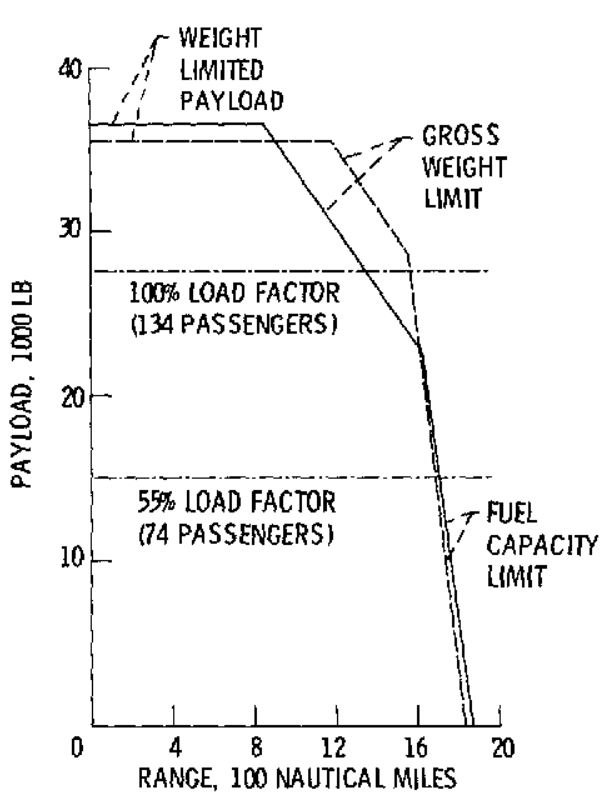

Figure 12. - B727-200 payload/ range characteristics. 0.84 Mach number. $30,000 \mathrm{ft}$. altitude, standard day. 


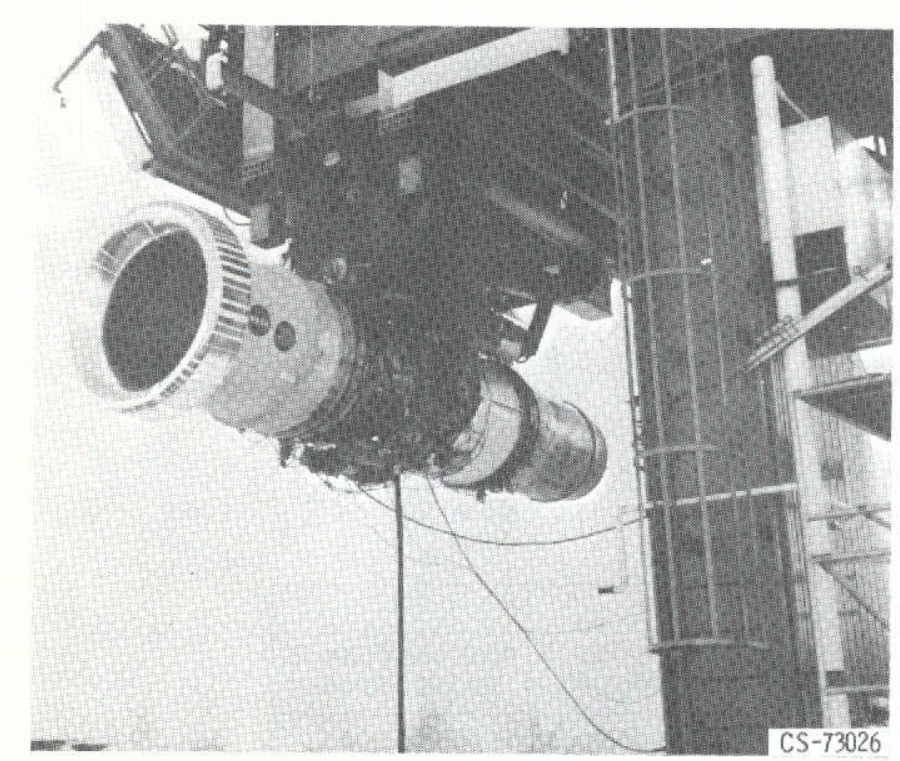

Figure 13. - JT8D-109 refan engine installed in the outdoor acoustic test facility at P\&WA.

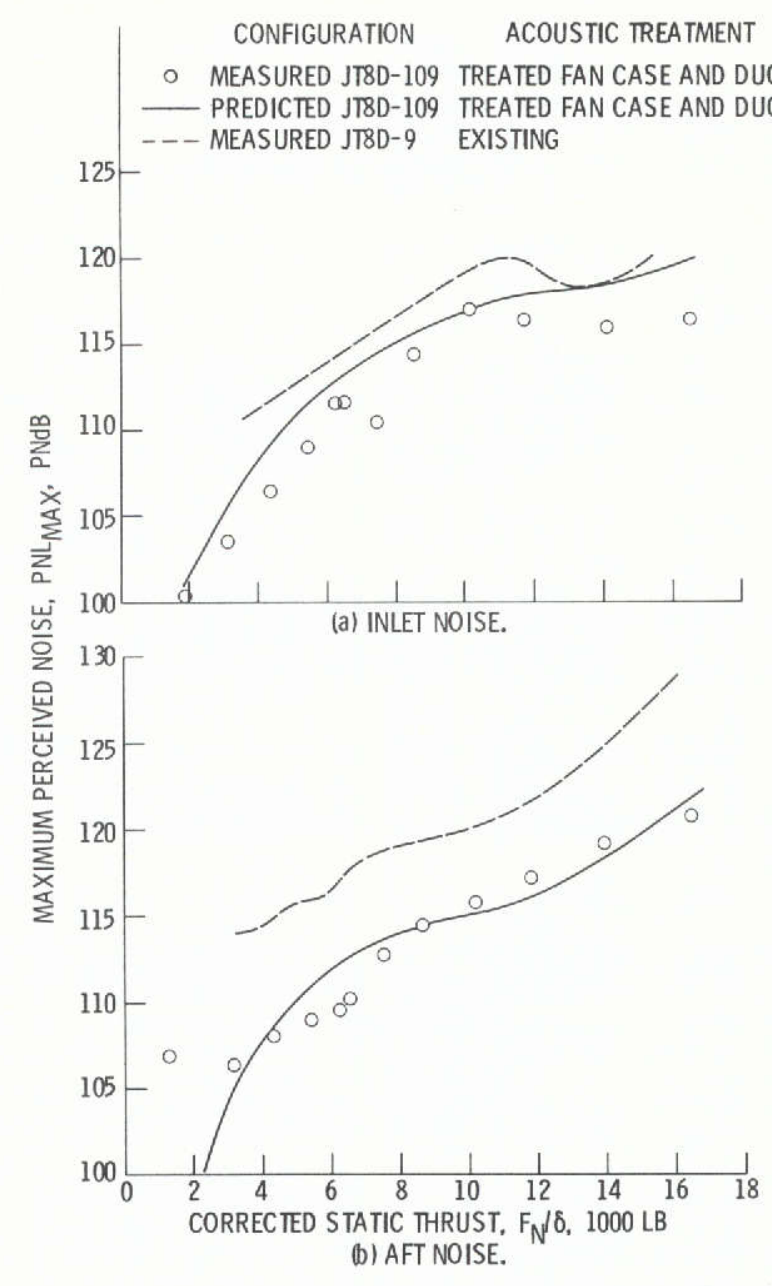

Figure 14. - Peak perceived noise level of engine at 200foot sideline. (Data supplied by P\&WA). 


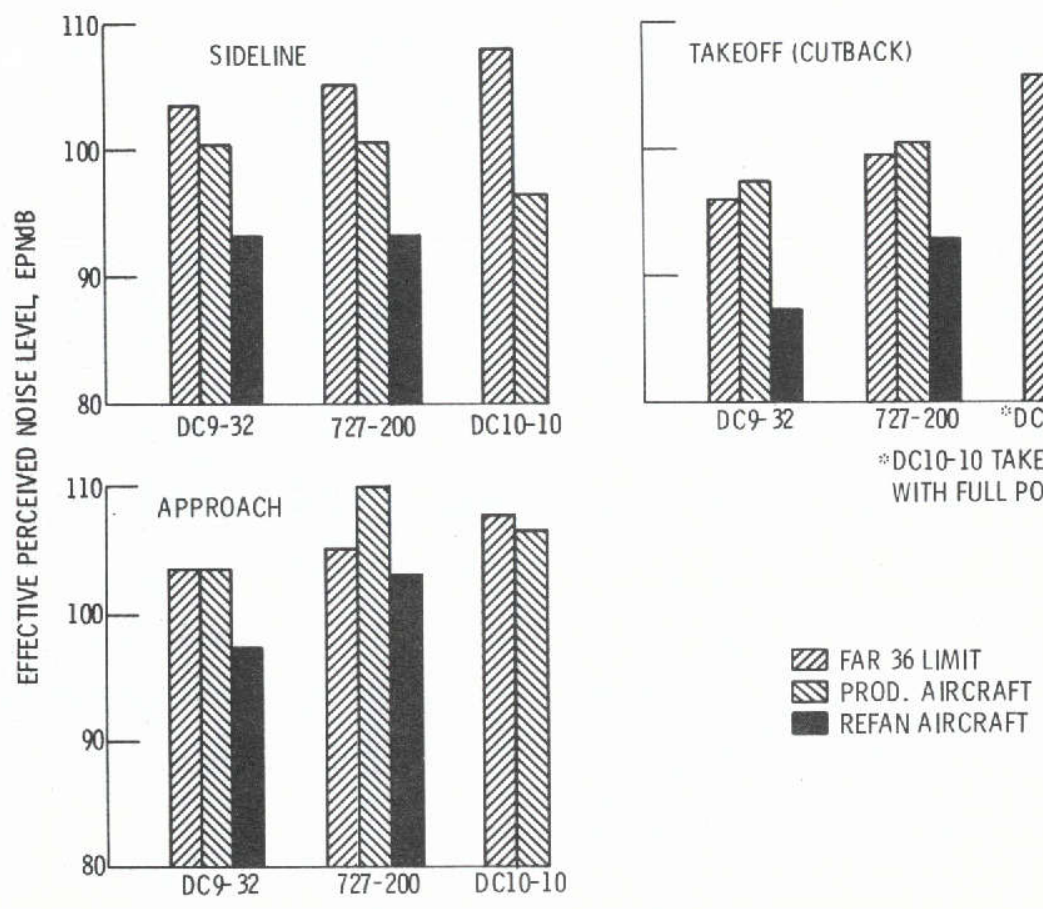

+

$\infty$
1
1
a

Figure 15. - Noise level comparison of refan aircraft with production aircraft and FAR part 36 limit. (Refan aircraft based on refan engine acoustic data.).

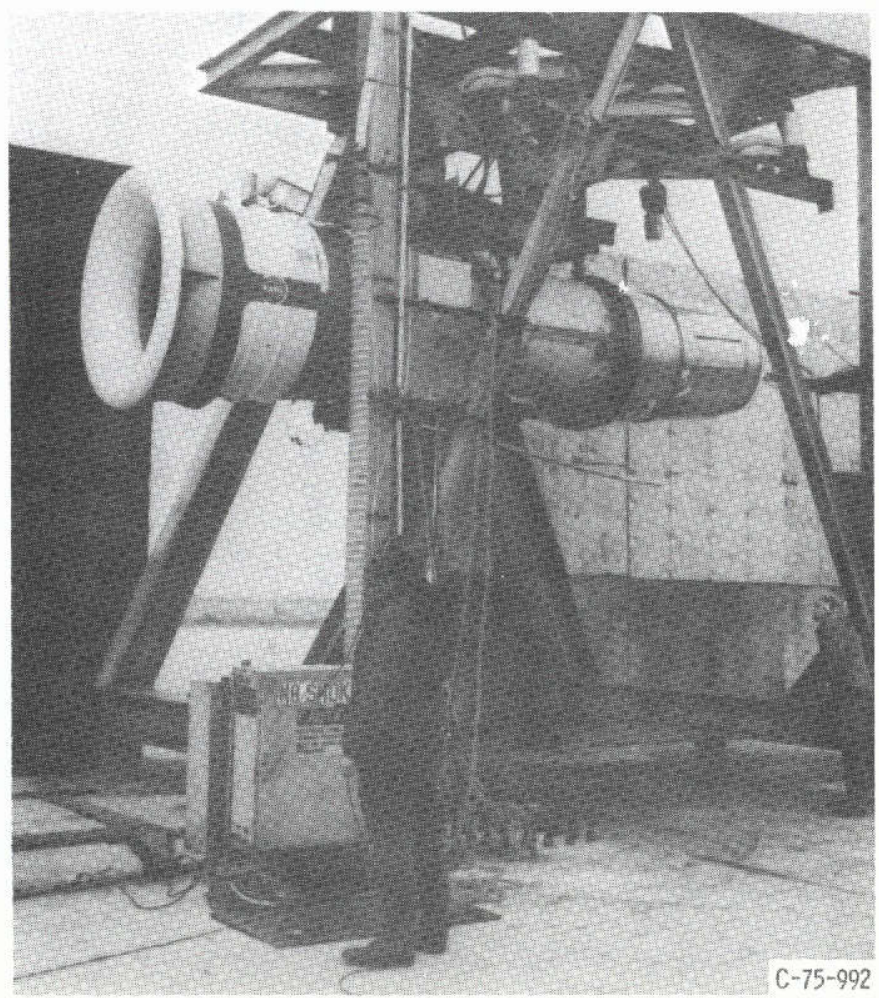

Figure 16. - B727 side-engine nacelle with refan engine installed in Boeing acoustic and performance outdoor test facility at Boardman, Oregon. 


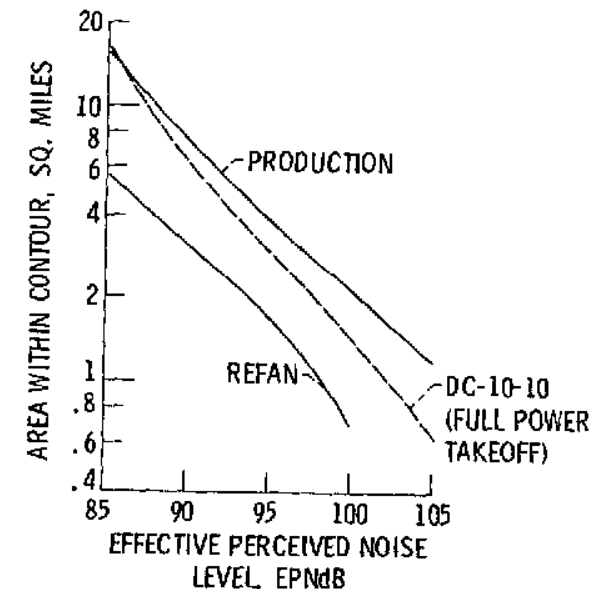

Figure 17, - DC-9-32 footprint contour areas. Cutback certification profile. Single segment approach. Takeoff gross weight, 108, $000 \mathrm{lb}$. (Refan contour areas based on refan engine acoustic data. I.

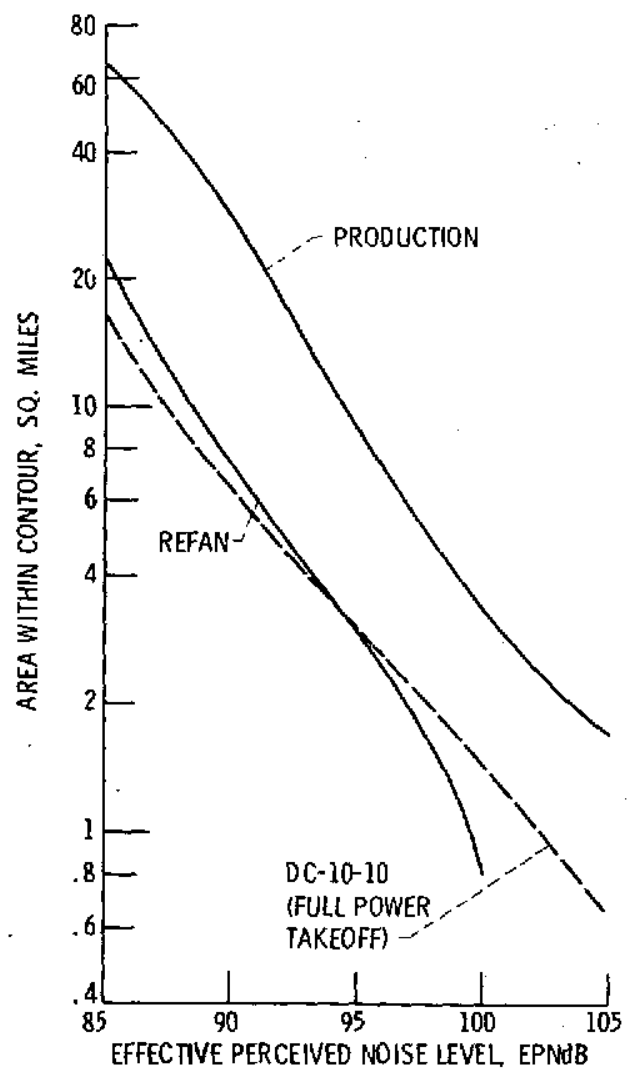

Figure 18. - B727-200 footprint contour areas. Cutback certiflcation profile. Single segment approach. Takeoff gross weight, 172,500 lb. (Refan contour areas based on refan engine acou stic data.). 


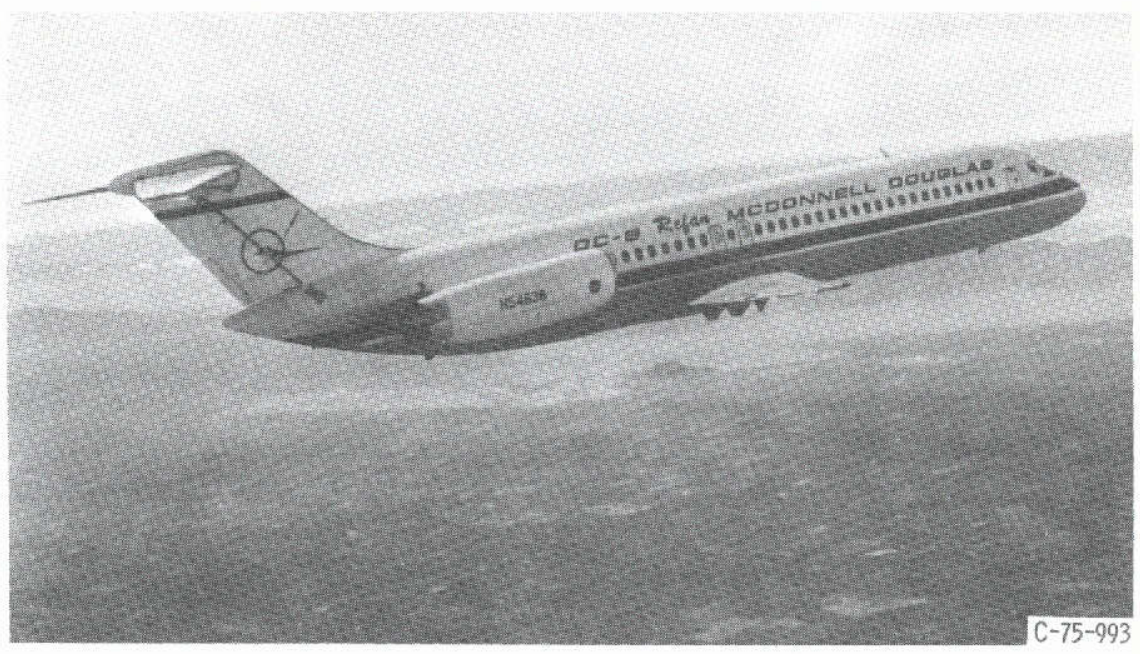

Figure 19. - Refan DC-9 airplane in flight.

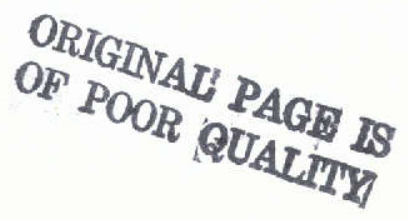

NASA-Lewis 